\title{
Prescription writing error in general practice: A cross sectional study at tertiary care hospital in Hyderabad, Pakistan
}

\author{
Raheela Saleem ${ }^{1}$, Abdullah Dayo ${ }^{1}$, Muhammad Ali Ghoto ${ }^{1}$ \\ Muhammad Akram², Mudassar Iqbal Arain ${ }^{1}$, Abbas $\mathrm{Ali}^{3}$. \\ 1. Department of Pharmaceutics, Faculty of Pharmacy, University of Sindh, Jamshoro, Pakistan. \\ 2. Department of Pharmacology, Faculty of Pharmacy University of Sindh, Jamshoro, Pakistan, \\ 3. Department of Mathematics and Statistics, Quaid Awam Engineering and Science University, Nawabshah, \\ Pakistan,
}

\begin{abstract}
Prescription is an instruction written by a medical practitioner to pharmacist which contains drug name, dose, frequency, directions for compounding, advices for drug consumption etc. Drug induced morbidity is an important problem in ambulatory care patients and its one of the major factor is prescription error. Therefore, the present study was performed to assess the current prescription writing trend for identifying frequent errors and proposing the ways by which these can be overcome. A cross sectional study was conducted by collecting 2120 prescriptions written in outpatient department (OPD) of tertiary care hospital. The prescribing errors were identified on the basis of WHO guidelines for prescription writing and current guidance published in British National Formulary. Most of the prescriptions evaluated did not follow the proper guidelines. Patient's weight, prescriber's contact, duration of therapy and drug generic name were missed in more than $90 \%$ of prescriptions. A significant number of prescriptions were also found to be illegibly written. Overall, prescription wring trend was worse and there is a need of training for proper prescription writing. Implementation of computerized order entry system and participation of pharmacists at all points of medication process may also substantially improve prescription writing trend.
\end{abstract}

Key words: Prescription; error; WHO Standards; BNF; General practice

\section{Introduction}

Prescription is an order written by medical practitioner containing directions for pharmacists to compound or/and dispense medications and for patients regarding their consumption (Tripathi KD, 2008). Although every country may have different regulations of prescription writing but most of them including Pakistan adopted the guidelines defined by World Health Organization (De Vries TP et al., 1995) and British National Formulary (BNF, 2010). These guidelines suggest that prescriptions should contain complete prescriber's, patient's and drug's information also including directions for using the drugs.

Errors in prescription writing can lead to patient injury by drugs. Dean, B et al., 2000 defined prescribing error as; "A clinically meaningful prescribing error occurs when, as a result of a prescribing decision or prescription writing process, there is an unintentional significant (1) reduction in the probability of treatment being timely and effective or (2) increase in the risk of harm when compared with generally accepted practice". Prescription writing error was found to be the most common among all medication errors as reported in a multi centre study (Stubbs Jean et al., 2006). In another study, they demonstrated that prescription and administration errors are two most common types of medication errors (Bates DW et al., 1995). High frequency of prescription errors was also found in antibiotics' prescriptions concerning completeness of prescriptions, indications for the use of antibiotics and obtaining microbiological cultures before starting antibiotics (Laura Calligaris et al., 2009).

A large number of reports have been published worldwide on prescription errors. In critical care units of UK, out of 21589 new prescriptions, 3141 (15\%) prescriptions were found to contain one or more errors in which $14.2 \%$ of the errors were categorized as not writing the order according to BNF recommendations and $916(19.6 \%)$ errors were categorized as potentially life threatening (Ridley et al., 2004). A descriptive retrospective study in Mexico city showed that 53\% of total prescriptions contained potential prescription errors and most of the errors were due to omissions (Jose Antonio et al., 2009). Stubbs Jean et al., 2006 reported that prescription errors were the most common in UK mental health units, accounted for $77.4 \%$ of total medication errors. A retrospective cross-sectional study in southeastern Brazil demonstrated that $44.4 \%$ of high alert drugs prescribed contained errors and $86.5 \%$ of errors were related to missing information (Rosa MB et al., 2009).

Unfortunately in Pakistan although number of prescription errors is too high but only few studies have been performed. A report from a local news paper demonstrated that around 7000 mortalities occur every year in Pakistan due to medication errors (The Nation, 2011). A study performed in a hospital of Lahore, demonstrated that out of total prescribed medications, $39.28 \%$ of medications were found to contain prescribing 
errors including dose, poly pharmacy, writing ambiguous order, inappropriate drug combinations and dosage form errors (Shawahna Ramzi et al., 2008). Another study performed at teaching hospital D.I Khan, Pakistan revealed that about $70 \%$ of medication errors occurred during ordering stage of prescriptions (Amin Adnan et al., 2010).

The present study has focused to understand current prescription writing trends and to identify the most frequent prescription errors in general practice at tertiary care hospital. This study could help to identify the common errors and the ways by which these can be resolved.

\section{Methods}

A cross sectional study was conducted at outpatient department (OPD) of a hospital located in Hyderabad, Pakistan. It was a tertiary care hospital proving health services to diverse patient populations. 2120 prescriptions were randomly collected at pharmacy located nearby outpatient department (OPD) during the period of three months. The collected prescriptions were analyzed by experienced clinical pharmacists for the presence of prescription errors depending on prescribing parameters defined by World Health Organization (De Vries TP et al., 1995) and current guidance published in British National Formulary (BNF, 2010). Data was evaluated using an analysis sheet that includes all essential parameters defined by the WHO and BNF for prescription writing. These parameters include prescriber's information (Name, telephone number, address and signature), patient's information (name, age, gender, weight and address/telephone number), drug's information (drug brand/generic/mixed name, strength, dose, frequency, route of administration, duration and quantity of prescribed drugs) and miscellaneous information (directions for patients, legible hand writing and date on prescription). Every prescription was screened to check if it contained all the parameters mentioned in analysis sheet to meet the criteria of good prescription writing.

\section{DATA ANALYSIS}

Microsoft office and Descriptive Statistics used for analyzing the collected data, through Computational software SPSS 17.0 version.

\section{Results}

In this study we analyzed a total of 2120 prescriptions and only $75(3.5 \%)$ prescriptions contained all the above mentioned parameters. In case of prescriber's information (Table 01), most of the prescriptions 2015 (95\%) were failed to contain telephone number, however 2007 (94.7\%) prescriptions had prescriber's signature. The prescriber's name and address were absent in 1726 (81.4\%) and 1752 (82.6\%) prescriptions respectively.

\begin{tabular}{|l|l|l|}
\hline \multicolumn{3}{|c|}{ TABLE 01: ANALYSIS OF PRESCRIBER'S INFORMATION } \\
\hline WHO/BNF Parameters & PRESENT & ABSENT \\
\hline Name & $394(18.6 \%)$ & $1726(81.4 \%)$ \\
\hline Address & $368(17.4 \%)$ & $1752(82.6 \%)$ \\
\hline Telephone number & $105(5 \%)$ & $2015(95 \%)$ \\
\hline Signature & $2007(94.7 \%)$ & $113(5.3 \%)$ \\
\hline
\end{tabular}

Regarding analysis of patient's information (Table 02) we found that only few prescriptions had been identified as being lacking the name and age. On the other hand a large proportion of prescriptions did not possess the weight (95.5\%), address/telephone number (86.3\%) and gender $(70.3 \%)$.

Pertaining to drug's information on prescription (Table 03), we observed that 1658 (78.2\%), 186 $(8.8 \%)$ and $145(6.8 \%)$ prescriptions contained brand, generic and mixed names respectively. However, in 131 (6.2\%) prescriptions names of drugs were not readable due to illegible hand writing. While analyzing the strength, route of administration and duration of therapy we observed that they were missing in large number of prescriptions $1773(83.6 \%), 1647(77.7 \%)$ and 1977 (93.3\%) respectively. Furthermore, $832(39.2 \%)$ prescriptions did not include dose of medications. However, majority of prescriptions 1878 (88.6\%) contained drug frequency.

\begin{tabular}{|l|l|l|}
\hline \multicolumn{3}{|c|}{ TABLE 02: ANALYSIS OF PATIENT'S INFORMATION } \\
\hline WHO/BNF Parameters & PRESENT & ABSENT \\
\hline Name & $2101(99.1 \%)$ & $19(0.9 \%)$ \\
\hline Age & $2070(97.6 \%)$ & $50(2.4 \%)$ \\
\hline Weight & $96(4.5 \%)$ & $2024(95.5 \%)$ \\
\hline Gender & $629(29.7 \%)$ & $1491(70.3 \%)$ \\
\hline Address/Telephone number & $290(13.7 \%)$ & $1830(86.3 \%)$ \\
\hline
\end{tabular}




\begin{tabular}{|l|l|l|}
\hline \multicolumn{3}{|c|}{ TABLE 03: ANALYSIS OF DRUG'S INFORMATION } \\
\hline WHO/BNF Parameters & PRESENT & ABSENT \\
\hline Brand name & $1658(78.2 \%)$ & $462(21.8 \%)$ \\
\hline Generic name & $186(8.8 \%)$ & $1934(91.2 \%)$ \\
\hline Mixed & $145(6.8 \%)$ & $1975(93.2 \%)$ \\
\hline Unreadable & $131(6.2 \%)$ & $1989(93.8 \%)$ \\
\hline Strength & $347(16.4 \%)$ & $1773(83.6 \%)$ \\
\hline Dose & $1288(60.8 \%)$ & $832(39.2 \%)$ \\
\hline Route of administration & $473(22.3 \%)$ & $1647(77.7 \%)$ \\
\hline Frequency & $1878(88.6 \%)$ & $242(11.4 \%)$ \\
\hline Duration & $143(6.7 \%)$ & $1977(93.3 \%)$ \\
\hline
\end{tabular}

\begin{tabular}{|l|l|l|}
\hline \multicolumn{3}{|c|}{ TABLE 04: MISCELLANEOUS } \\
\hline WHO/BNF Parameters & PRESENT & ABSENT \\
\hline Date on prescription & $2031(95.8 \%)$ & $89(4.2 \%)$ \\
\hline Legible handwriting & $1393(65.7 \%)$ & $727(34.3 \%)$ \\
\hline Directions for patient & $365(17.2 \%)$ & $1755(82.8 \%)$ \\
\hline
\end{tabular}

A large number of deficiencies were observed in case of directions for patients (Table 04), they were missed in $1755(82.8 \%)$ prescriptions. Date was present on most of the prescriptions 2031 (95.8\%) but $727(34.3 \%)$ prescriptions were not written in legible handwriting.

Overall in our study, a total number of 24564 prescription errors were found (Fig. 01). Approximately half $10973(44.7 \%)$ of the total errors were related to missed drug information. On the other hand prescriber's and pateint's information related parameters were absent in $5606(22.8 \%)$ and $5414(22.0 \%)$ prescriptions respectively. Finally, approximately one tenth $2571(10.5 \%)$ of miscellaneous (date, legible hand writing \& directions for patients) type errors were found.

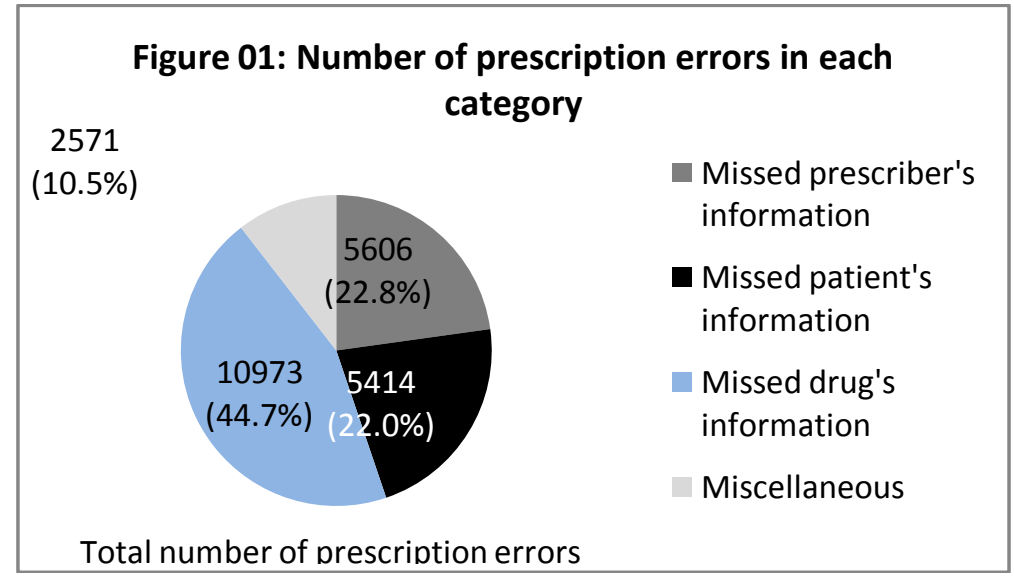

\section{Discussion}

A total number of 2120 prescriptions were analyzed on the basis of prescription writing parameters defined by World Health Organization (De Vries TP et al., 1995) and British National Formulary (BNF 2010). Our study revealed that prescriptions were written so worse, only $75(3.5 \%)$ of total prescriptions were found to possess all parameters.

Prescriber's information on prescription is necessary as it helps the dispensing pharmacist to contact prescriber in the case, if any clarification regarding prescribed drugs is needed. However, our results showed that a large number of prescriptions were missing to contain complete prescriber's information. Prescriber's name and signature were absent in $81.4 \%$ and $5.3 \%$ of prescriptions respectively (Fig. 02). Our results are in contrast to as reported by Irshaid Y.M et al. (2005) who found $16.7 \%$ and $18.1 \%$ prescriptions were deficient in prescriber's name and signature respectively. Our findings demonstrated that majority of prescriptions $82.6 \%$ and $95 \%$ did not contain address and telephone number of prescriber respectively. The study by Vaishali D et al. (2011) revealed the similar results; they identified that $78.2 \%$ and $89.6 \%$ of prescriptions were deficient in prescriber's address and telephone number respectively. 
Similarly, complete patient's information on prescription is also important as, it helps the pharmacist to review the order properly and can contact patient if needed. Patient's weight and age are the most important parameters for dose calculation; it helps the pharmacist to review the prescribed dose if they are mentioned on prescription. In our study, absence of patient's weight in most of the prescriptions (95.5\%) (Fig. 02) corresponds to the findings of Vaishali D et al. (2011) and Irshaid Y.M et al. (2005) where none of prescriptions were found to have patient's weight. Moreover, for proper selection of medications age plays a considerable role as many drugs are contraindicated in special age groups e.g. geriatrics and pediatrics. Our study revealed that only $2.4 \%$ of prescriptions lacked the patient's age. This result is analogous to that reported by Balbaid OM et al. (1998), where $10 \%$ of prescriptions missed the patient's age. There are some medications which are only prescribed for one gender for other they are contraindicated. Thus, to mention the patient's gender on prescription is paramount. Our data showed that a substantial number of prescriptions $70.3 \%$ were failed to contain patient's gender which is dissimilar to the findings of Vaishali D et al. (2011) and Balbaid OM et al. (1998) who found only $10 \%$ and $4.1 \%$ of prescriptions with missed gender respectively. But this finding is fairly similar to Irshaid Y.M et al. (2005) reported $48.7 \%$ prescriptions lacked the patient's sex. In case of patient's address/telephone number, our data revealed that a larger proportion of prescriptions $(86.3 \%)$ did not possess this specific parameter. Our results are parallel to the findings by Vaishali D et al. (2011) where no prescription was analyzed to contain patient's address.

Pertaining to drug's information, our finding shows that $78.2 \%, 8.8 \%$ and $6.8 \%$ of the prescriptions contained brand, generic and mixed name (generic and brand) of drugs respectively (Fig. 02). This data is on par with the findings of Anuja A et al. (2010) who reported that only $7.4 \%$ of prescriptions from a pediatric outpatient department contained generic names. On the other hand, Irshaid Y.M et al. (2005) had reported that brand name was written in $50.1 \%$, generic name in $15.1 \%$ and mixed name in $28.3 \%$ of prescriptions. The frequent prescribing of drugs by brand names in our study may be considered as evidence of vigorous promotional activities by pharmaceutical companies. However, prescriptions written by generic names is beneficial in the sense that dispensing pharmacist can dispense the most economical and efficacious brands to patients. Nonetheless, $6.2 \%$ of prescriptions were not readable. The strength is important to be mentioned where products are available in more than one strengths in the market. However, our result shows that strength was missing in more than $3 / 4^{\text {th }}$ of prescriptions. While Vaishali D et al. (2011), Irshaid Y.M et al. (2005) and Stubbs Jean et al. (2006) found that $26.8 \%, 52.8 \%$ and $3.6 \%$ of prescriptions were without strength. Proper quantity of the drug is necessary to be taken by patients for optimal and safer drug effects. So, it is the responsibility of prescriber to properly mention the doses on prescriptions. Our result shows that $39.2 \%$ of prescriptions were lacked the doses. This result corresponds to the finding of Vaishali D et al. (2011) where, in $35.1 \%$ of prescriptions doses were not mentioned clearly. However, Balbaid OM et al., (1998) reported that $7.6 \%$ of prescriptions did not contain dose at all. There are some drugs which are given by more than one route; in these cases it is important to mention the preferred route for a patient. Our results (Fig. 02) were found dissimilar to the findings of Stubbs Jean et al. (2006) they mentioned only $1.5 \%$ of prescriptions did not possess the route. The frequency and duration of therapy are also essential elements of prescription writing. We found that a huge number of prescriptions (93.3\%) did not carry duration. On contrary, Khaja et al. (2008) and Vaishali D et al. (2011) reported only $18.5 \%$ and $26.2 \%$ of prescriptions missed the length of treatment. In our study, little more than one tenth of prescriptions bypassed the dosing frequency whereas; Khaja et al. (2008) and Balbaid OM et al. (1998) reported $3.7 \%$ and $6.9 \%$ of prescriptions lacked the frequency.

Moreover, our data shows that $4.2 \%$ of prescriptions were not dated (Fig. 02). Our results are similar to that of Francois P et al. (1997) and Balbaid OM et al. (1998) who reported that 4.5\% and $8.7 \%$ of prescriptions missed the date. However, more than half of the prescriptions did not acquire date as reported in a survey of antibiotics' prescriptions from Italian Hospital (Laura et al., 2009). The prescriptions which are not written legibly, they may be the source of fatal injuries (Hester DO, 2001) and a leading cause of death as reported by Boehringer et al. (2007). Our finding that $34.3 \%$ of prescriptions were illegibly written is in contrast with Balbaid OM et al. (1998) they reported that only $7.2 \%$ of prescription were found illegible. On the other hand Meyer TA (2000) and Makonnen E et al. 2002 revealed 15\% of prescriptions which were not written legibly. To mention the directions for patients (e.g specific timing for taking medicine or follow up advice) on prescriptions is also important. Our result revealed that $82.8 \%$ of prescriptions did not comprise the directions; this is similar with the findings of Vaishali D et al. (2011) who reported that none of the prescription contained advice for follow up and approximately half missed the instructions for patients. 


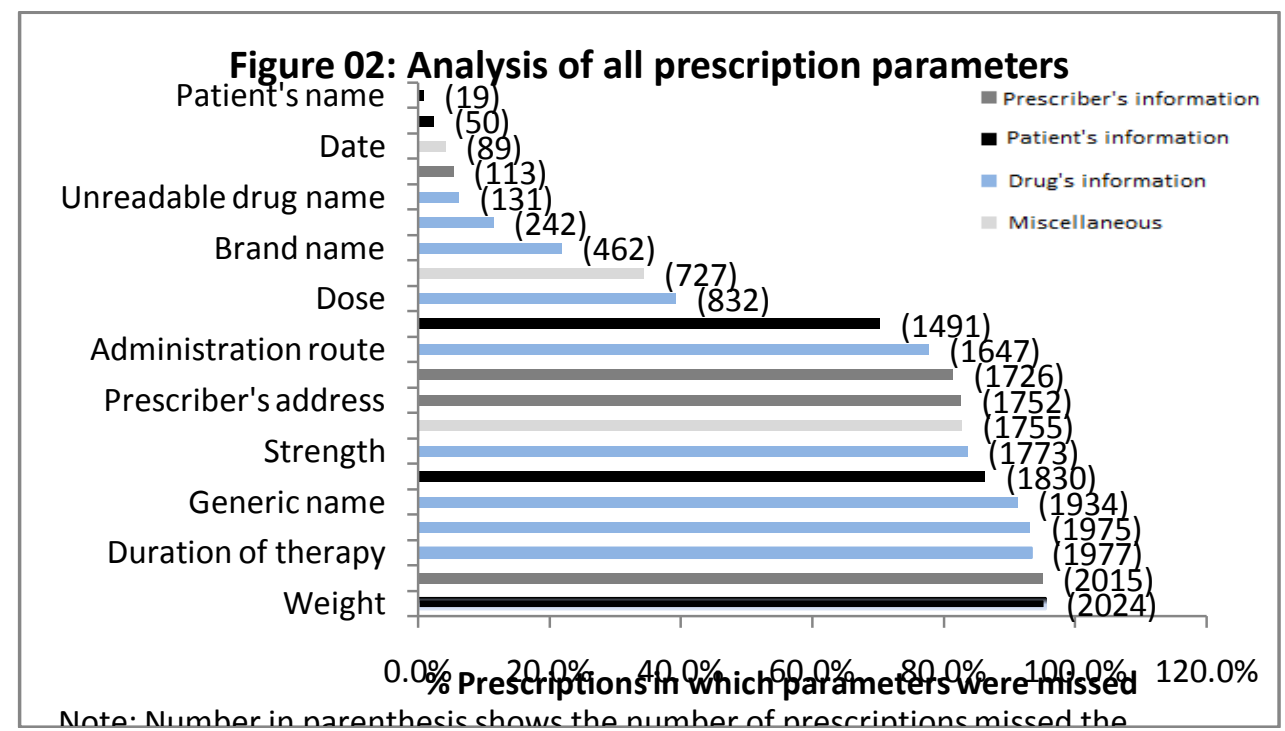

Various suggestions had been proposed by different researchers for improving prescription writing. An intervention study in a Dutch intensive care unit reported to reduce prescribing errors, when onward pharmacists were participated (Klopotowska JE et al., 2010). Other researchers suggested for using electronic prescribing systems to reduce the errors (Nightingale PG et al., 2000; Javier Rodr1'guez-Vera F et al., 2002). Nonetheless, Bates DW et al. (1995) and Anton C et al. (2004) had studied that implementation of computer based prescribing systems greatly reduced prescription errors. As our recommendations, training for prescribers regarding standard prescription guidelines, introduction of electronic prescribing systems and involvement of clinical pharmacists at all points of medication process also including evaluation of prescriptions, may greatly improve prescription writing trend and be helping to reduce errors.

\section{Conclusion}

Our study revealed serious problems in prescription writing trend as most of the prescriptions did not follow the proper guidelines. Lack of patient's weight, prescriber's contact, duration of therapy and drug generic name were the most frequent errors. Moreover, a significant number of prescriptions were also written illegibly. There is a need of training and educational programs for prescribers regarding proper prescription writing. Implementation of proper error reduction strategies such as; error reporting, use of computerized prescription order entry system and software programs which shows caution in case of errors and by appreciating the role of pharmacists at all points of medication process may greatly improve prescription writing trend and reduce the errors.

\section{References}

[1]. Amin Adnan, Shah S.M.A, Hussain Abid (2010). Prescribing and Dispensing Practices in a Public sector Pedriatric Ward in D.I.Khan, Pakistan. Pak Journal of medical research; Vol. 49, No. 3.

[2]. Anton C, Nightingale PG, Adu D, Lipkin G, Ferner R E (2004). Improving prescribing using a rule based prescribing system. Qual Saf Health Care; 13:186-190.

[3]. Anuja A Pandey, Subhash B Thakre, and Prakash R Bhatkule (2010). Prescription Analysis of Pediatric Outpatient Practice in Nagpur City. Indian J Community Med; 35(1): 70-73.

[4]. Balbaid OM, Al-Dawood KM (1998). Assessment of physician's prescribing practices at Ministry of Health Hospitals in Jeddah City, Saudi Arabia. Saudi medical journal; 19:28-35.

[5]. Bates DW, Cullen DJ, Laird N, Petersen LA, Small SD, Servi D, Laffel G, Sweitzer BJ, Shea BF, Hallisey R, et al. (1995). Incidence of adverse drug events and potential adverse drug events: Implications for prevention, JAMA; 274:29-34.

[6]. Boehringer PA, Rylander J, Dizon DT, Peterson MW (2007) Improving the Quality of the Orderwriting Process for Inpatient Orders in a Teaching Hospital. Q Manage Health Care; 16(3):215-218.

[7]. British National Formulary (2010). BNF, $60^{\text {th }}$ edition, British Medical Association and Royal Pharmaceutical Society of Great Britain.

[8]. De Vries TP, Henning RH, Hogerzeil HV, Fresle DA (1995). Guide to good prescribing: A practical manual, Geneva world health organization; 66-78 (WHO/DAP/94.11).

[9]. Dean B, Barber \&, Schachter M (2000). What is a prescribing error? Quality in Health Care; 9:232-237.

[10]. Francois P, Chirpaz E, Bontemps H, Labarere J, Bosson JL, Calop J (1997). Evaluation of prescription-writing quality in a French university hospital. Clinical Performance and Quality Health Care; 5 (3): 111-115

[11]. Hester DO (2001). Do you see what I see? Illegible handwriting can cause patient injuries. J Ky Med Assoc ; 99:187.

[12]. Irshaid Y.M, Al Omrany M, Hamdi A.A, Adjapon-Yamoah K.K and Mahfouz A.A (2005). Compliance with good practice in prescription writing at outpatient clinics in Saudia Arabia. East Mediterr Health J; 11(5-6):922-928

[13]. Javier Rodrı'guez-Vera F, Marı'n Y, Sa' nchez A, Borrachero C, Pujol E (2002). Illegible handwriting in medical records. J R Soc Med; 95:545-546. 
[14]. José Antonio Corona-Rojo, Marina Altagracia-Martínez, Jaime Kravzov-Jinich, et al. (2009). Potential prescription patterns and errors in elderly adult patients attending public primary health care centers in Mexico City. Clinical Interventions in Aging; volume: 4, Pages $343-350$.

[15]. Khaja Al K A J , R P Sequeira,T M Al-Ansari, A H H Damanhori (2008). Prescription writing skills of residents in a family practice residency programme in Bahrain. Postgrad Med J; 84:198-204.

[16]. Klopotowska JE, Kuiper R, van Kan HJ, et al. (2010). On-ward participation of a hospital pharmacist in a Dutch intensive care unit reduces prescribing errors and related patient harm: an intervention study. Crit Care; 14:R174.

[17]. Laura Calligaris, Angela Panzera, Luca Arnoldo, Carla Londero, Rosanna Quattrin, Maria G Troncon, Silvio Brusaferro (2009). Errors and omissions in hospital prescriptions: A survey of prescription writing in a hospital. BMC Clinical Pharmacology; 9: 9.

[18]. Makonnen E, Yoseph M, Berhane Y (2002). Quality of prescription at a tertiary care pharmacy in Addis Ababa. Ethiopian Medical Journal; 40 (3): 233-239.

[19]. Meyer TA (2000) Improving the quality of the order-writing process for inpatient orders and outpatient prescriptions. Am J Health System Pharm; 57 (suppl 4): 4-22

[20]. Nightingale PG, Adu D, Richards NT, et al (2000). Implementation of rules based computerized. Bed side prescribing and administration: intervention study. BMJ; 320:750-3.

[21]. Ridley S.A, Booth S.A, Thompson C.M and the Intensive Care Society's Working Group on Adverse Incidents (2004). Prescription errors in UK critical care units. Anaesthesia, 59, pages 1193-1200.

[22]. Rosa MB, Perini E, Anacleto TA, Neiva HM, Bogutchi T (2009). Errors in hospital prescriptions of high-alert medications. Rev Saude Publica; 43(3):490-498.

[23]. Shawahna R, Rahman NU (2008). Prescribing errors in psychiatry department: An audit from a hospital in Lahore, Journal of Pakistan Psychiatric Society, Audit article page 31.

[24]. Stubbs Jean, Haw Camilla, Taylor David (2006). Prescription errors in psychiatry- A multicentre study. Journal of psychopharmacology; 20(4) 553-561.

[25]. The Nation News paper $\left(30^{\text {th }}\right.$ Dec 2011). A letter on medical errors.

[26]. Tripathi KD (2008).Essentials of medical pharmacology, 6th Edition, Jaypee Brothers medical publishers, New Delhi, pp. 03.

[27]. Vaishali D Phalke, Deepak B Phalke, Syed M M Aarif, Anjeney Mishra, Saudamini Sikchi, Piyush Kalakoti (2011). Prescription writing practices in a rural tertiary care hospital in Western Maharashtra, India. Australasian Medical Journal AMJ; 4, 1, 4-8. 